\title{
ARGILA DE BELTERRA - COBERTURA TERCIÁRIA DAS BAUXITAS AMAZÔNICAS
}

\author{
WERNER TRUCKENBRODT* e BASILE KOTSCHOUBEY*
}

\begin{abstract}
Belterra Clay is a uniform, yellowish kaolinitic clay lacking visible stratification. It overlies laterite plateaus with a maximum thickness of $20 \mathrm{~m}$. The clay is derived from a lateritic terrane occuring outside and within the Amazonian bauxite belt. Redistribution of clay material from the basal layers of the laterite zone by mud flow or sheet flood in a semiarid climate is suggested for the origin of Belterra Clay. Considering the history of Velhas surface a pliocene if not a mio-pliocene age for this clay cover cannot be ruled out.
\end{abstract}

INTRODUÇÃO A província bauxitífera do norte do Brasil está localizada em sua maior parte na Bacia Amazônica, mas estende-se até o flanco NW da Bacia do Parnaiba, onde forma o distrito de Paragominas. Ela se desenvolveu, por conseguinte, nas áreas separando o Escudo das Guianas, o Craton Amazônico e o Craton de São Luís.

As bauxitas dessa região são sobrepostas por argilas que podem atingir até $20 \mathrm{~m}$ de espessura (Sombroek, 1966; e Assad, 1973). Essa cobertura argilosa tem sido. denominada Belterra Clay (Argila de Belterra), de acordo com o nome de uma vila situada a cerca de $40 \mathrm{~km}$ a SW de Santarém, onde se encontram ocorrências típicas deste material (Sombroek, op. cit.)

Existem diferentes interpretaçð̃es sobre a gênese da Argila de Belterra. Sombroek (1966) considera-a como um depósito lacustre do Plioceno ou Pleistoceno cobrindo grande parte da regiåo Amazônica (vide também Sioli, 1959) e sugere como área-fonte desse material a cadeia andina. Entretanto, Klammer (1971) interpreta-a como sendo a parte superior do Grupo Barreiras, representando o horizonte A extremamente lixiviado do próprio perfil bauxítico. Dennen e Norton (1977) e Aleva (in Krook, 1979) defendem a mesma idéia. Wolf e Silva (1973) aventam a hipótese de que a Argila de Belterra representa o produto de um processo pedogenético in situ a partir da própria sequêencia bauxítica. Em publicação mais recente, Grubb (1979) ressalta também a relação íntima existente entre a Argila de Belterra e a bauxita, mas sugere transporte e deposição da argila com base na presença de nódulos de gibbsita na parte inferior da cobertura argilosa, que são interpretados como sendo de orgem coluvial.

Essas interpretaçð̃es conflitantes sobre a origem da Argila de Belterra motivaram os autores a estudarem em detalhe essa sequêencia argilosa a fim de estabelecer sua proveniência e seu ambiente de formação.

Aspectos geográficos e geológicos A distribuição geográfica da Argila de Belterra atinge, segundo Klammer (1971), mais de 1 milhão de $\mathrm{km}^{2}$, o que é uma estimativa certamente exagerada. Uma parte das ocorrências (as situadas entre Manaus e Imperatriz) é apresentada na Fig. 1.

A superfície acentuadamente plana da sequência de Belterra é muito característica (Fig. 2) e facilita a locali- zação das lateritas sotopostas. Esse plano, de altitude entre 100 e $350 \mathrm{~m}$, mostra um leve declive para o eixo do vale do Amazonas. As al turas máximas, em torno de $350 \mathrm{~m}$, encontram-se ao sul de Paragominas, na região de Açailândia.

Sombroek (1966) sugeriu a idade plio-pleistocênica para a deposição da Argila de Belterra. As bauxitas e lateritas sotopostas, geralmente consideradas como sendo do Terciário Superior ou Quaternário (Grubb, 1979; Dennen e Norton, 1977; e Wolf e Silva, 1973), são provavelmente mais antigas (Eoceno/Oligoceno) conforme proposição de Krook (1979), com base na comparação entre as bauxitas da Amazônia e as do Suriname. Estudos paleontológicos na Formação Alter do Chão na Bacia do Amazonas (Daemon, 1975) e nossas observações na região de Paragominas evidenciaram que as bauxitas se formaram sobre rochas do Cretáceo Superior. Isso demonstra que os sedimentos Barreiras não podem ser considerados como rocha-matriz da sequiência laterito-bauxítica.

Estudos de Klammer (1971) no Baixo Amazonas mostraram que algumas falhas modificaram a topografia da Argila de Belterra e que a erosão, principalmente pleistocênica, diminuiu sua distribuição original.

METODOLOGiA Para o estudo da Argila de Belterra duas áreas foram selecionadas: a região entre os rios Nhamundá e Trombetas no Baixo Amazonas e a faixa de direção $\mathrm{N}-\mathrm{S}$ situada entre Paragominas e Açailândia (Fig. 1) ao longo da BR-010 (Belém-Brasília).

Foi coletado material de quatro poços situados no Baixo Amazonas, denominados Trombetas 1 e 2, e Nhamundá 1 e 2 , de trếs cortes da estrada BR-010 nos quilômetros 1603, 1508 e 1409, assim como de uma trincheira localizada no platô Miltônia, a cerca de $\mathbf{4 0} \mathrm{km}$ a SW de Paragominas. $O$ intervalo de amostragem dependeu da espessura do perfil, variando de 1 a $2 \mathrm{~m}$. Foram coletadas de cada seção no máximo dez amostras, pesando cada uma pelo menos $1 \mathrm{~kg}$.

Os trabalhos de laboratório abrangeram análises granulométricas por sedimentação, estudo do arredondamento dos grãos de quartzo (fração areia) e determinação do índice de clasticidade (Carozzi, 1958) dos fragmentos bauxíticos e ferruginosos e dos grãos de quartzo. .

* Do Núcleo de Ciências Geofísicas e Geológicas da Universidade Federal do Pará e bolsistas do Conselho Nacional de Desenvolvimento Científico e Tecnológico (CNPq) 


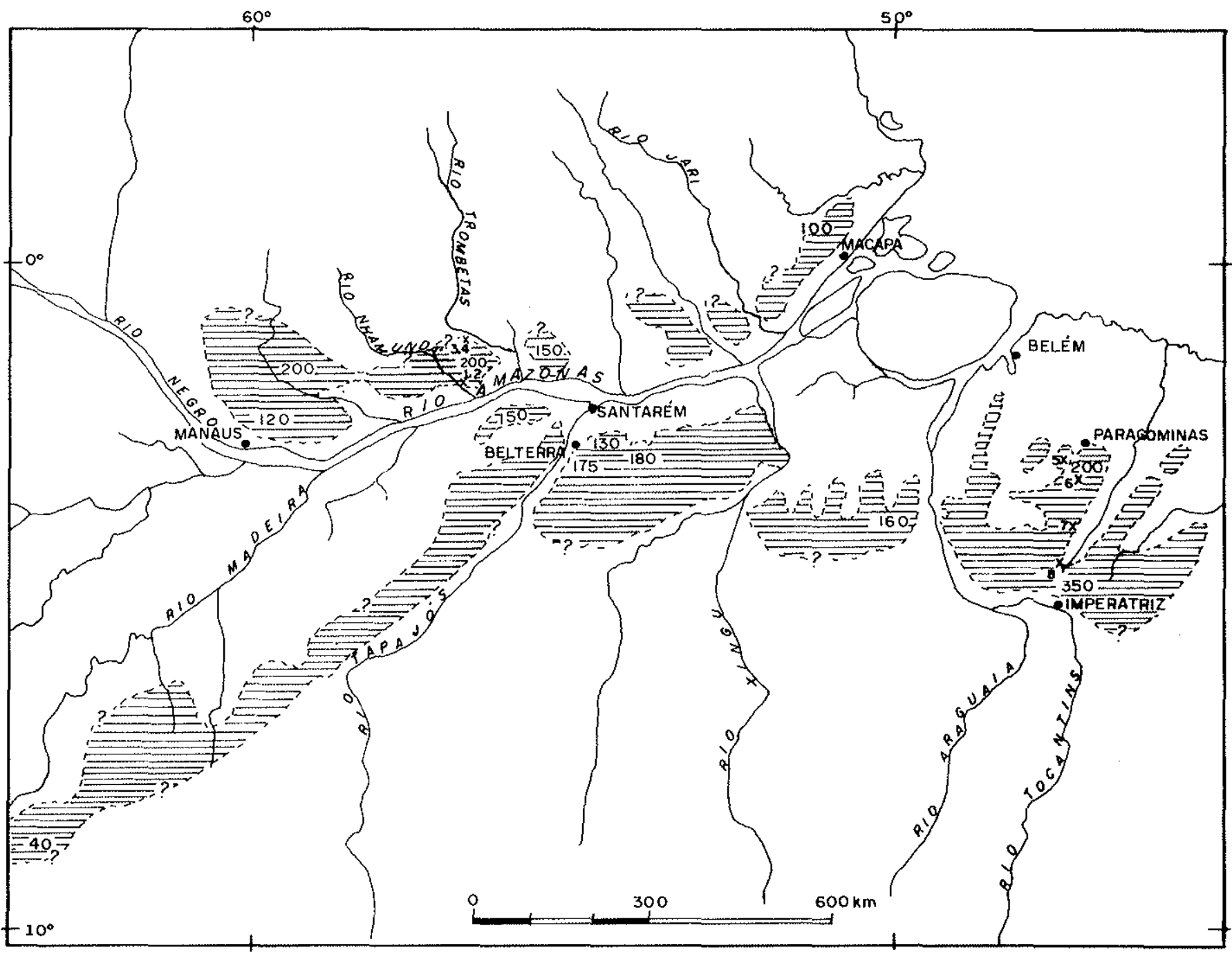

Figura I - Areas de ocorrência da Argila de Belterra na Amazônia (segundo Sombroek, 1966, com pequenas modificações). 1 a 8: perfis estudados; 1. Nhamundá 1; 2: Nhamundá 2; 3: Trombetas 1; 4: Trombetas 2; 5: Millônia; 6: Croantá (quilômetro 1603); 7: quilômetro 1508; e 8: Açailândia (quilômetro 1409)

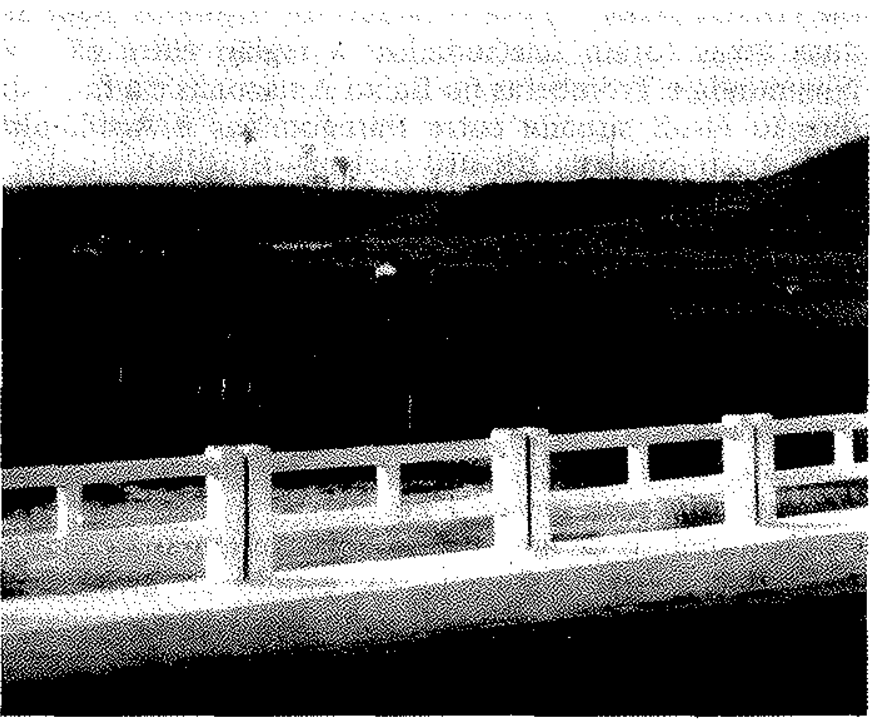

Figura 2 - Platô bauxitico próximo ao quilômetro 1603 da rodovia BR-010. Em seu topo encontra-se a Argila de Belterra aplainada no Plioceno Superior-Pleistoceno Inferior
A composição mineralógica das frações $<2 \mu, 2-6 \mu$ e 6-20 $\mu$ foi estudada por difração de raios X. Das frações 63-125 $\mu$ e 125-250 $\mu$ foram separados, com bromofórmio, os minerais pesados, posteriormente estudados ao microscópio.

Para fins comparativos, foram executadas análises gram nulométricas e mineralógicas de amostras da litomargem e da rocha-mãe bauxita.

RESULTADOS No campo, a Argila de Belterra apresenta um aspecto muito homogêneo, sem nenhuma estratificação visivel. Observa-se apenas uma ligeira mudança de cor, de alaranjado para amarelo, na parte superior dos perfis. As seqüencias estudadas variam entre 4 e $12 \mathrm{~m}$ de espessura (Tab. 1). Mas existem seções de até $20 \mathrm{~m}$.

$O$ contato entre a Argila de Belterra e a bauxita sotoposta é brusco e ligeiramente ondulado (Fig. 3), às vezes em forma de canal.

A composição mineralógica da Argila de Belterra é bastante monótona. A caulinita é o mineral predominante, constituindo cerca de $85 \%$ do sedimento. O restante distribui-se entre goetita, gibbsita, hematita e quartzo. 
Tabela I - Espessura da Argila de Belterra

\begin{tabular}{lclc}
\hline Baixo Amazonas & \multicolumn{3}{c}{ Região de Paragominas } \\
Perfil & Espessura & Perfil & $\begin{array}{c}\text { Espessura } \\
(\mathrm{m})\end{array}$ \\
Trombetas 1 & $(\mathrm{m})$ & $\mathrm{km} \cdot 1603 / \mathrm{BR}-010$ & 11 \\
Trombetas 2 & 6,0 & $\mathrm{~km} 1508$ & 12 \\
Nhamundá 1 & 10,0 & $\mathrm{~km} \mathrm{1409}$ & 8 \\
Nhamundá 2 & 6,6 & Miltônia & 6 \\
\hline
\end{tabular}

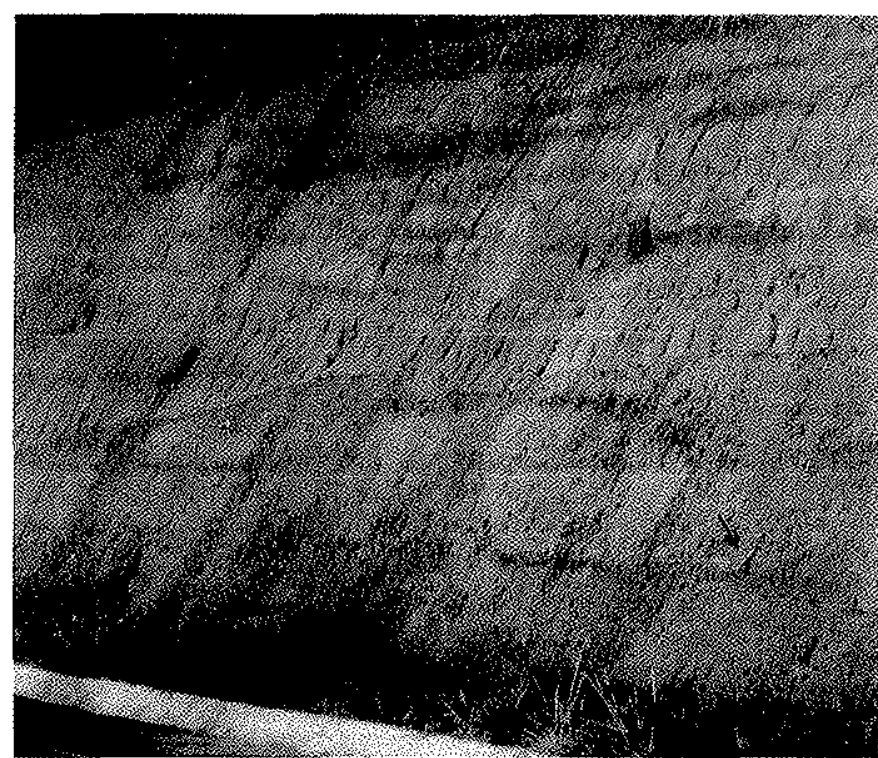

Figura 3 - Contato brusco e levemente ondulado entre a laterita e a Argila de Bellerra. Corte de estrada próximo ao $\mathrm{km} 1557$ da rodovia BR-010. O martelo ao lado direito indica a escala

Ocorrem também, no perfil Açailândia (quilômetro 1409 da rodovia BR-010), traços de ilita. Entre os minerais pesados predominam os ultra-estáveis: o zircão de hábito variável, a turmalina, o leucoxênio, o anatásio e o rutilo. Devem também ser mencionadas, no perfil Açailândia, pequenas quantidades de minerais menos estáveis: estaurolita e cianita.

As análises granulométricas mostram que o teor da fração inferior a $2 \mu$ (argila) atinge mais que $90 \%$ em todas as amostras estudadas. Os valores para os intervalos silticos $(2-6 \mu, 6-20 \mu, 20-63 \mu)$ são geralmente inferiores a $2 \%$ cada um, de modo que a fração síltica total raramente ultrapassa $5 \%$. A porcentagem da fração grosseira

Tabela 2 - Média dos teores de fração grosseira nos perfis da Argila de Belterra

$\begin{array}{ccc}\text { Norfil de } & \begin{array}{l}\text { Média } \\ \text { (\% peso) }\end{array} & \begin{array}{c}\text { Desvio- } \\ \text {-padrão } \\ (\% \text { peso })\end{array}\end{array}$

\section{A. Baixo Amazonas}

Nhamundá 1

Nbamundá 2

Trombetas

Trombetas 2

$\begin{array}{rr}7 & 3,6 \\ 4 & 5,8 \\ 6 & 3,8 \\ 10 & 3,0\end{array}$

0,5

0,3

B. Região de Paragominas

$\mathrm{km} 1603$

$\mathrm{km} 1508$

$\mathrm{km} 1409$

Miltônia

7

$(>63 \mu)$, que foi estudada mais detalhadamente, varia de 3,0 a 5,8 nos perfis do Baixo Amazonas e de 1,6 a 2,3 nos da região de Paragominas (Tab. 2). Esses valores são médias calculadas por seqüência amostrada. Assim, as porcentagens da fração grosseira nos perfis do Baixo Amazonas são mais elevadas que as das seqüências de $\mathrm{Pa-}$ ragominas. As rochas-matrizes da bauxita nessas áreas refletem a mesma tendência.

O principal mineral da fração argila é a caulinita enquanto a gibbsita e a goetita ocorrem apenas em pequenas quantidades. $O$ valor médio de goetita, estimado a partir da intensidade de suas reflexões difratométricas, é relativamente constante e situa-se em torno de $5 \%$. Os teores de gibbsita, entretanto, variam muito mais. No perfil de Açailândia (quilômetro 1409), esse mineral aparece só em traços enquanto no afloramento do quilômetro 1603 da rodovia $B R-010$ ele representa de $10 \%$ a $25 \%$ da fração argila. Além desses minerais ocorre também o anatásio em quantidades notáveis.

As frações sílticas contêm os mesmos constituintes essenciais, aos quais devem ser acrescentados o quartzo, o zircão e o rutilo, esses em quantidades subordinadas. Os difratogramas mostram nitidamente que a gibbsita e o quartzo aumentam relativamente do silte fino ao silte grosseiro, enquanto a caulinita apresenta um comportamento inverso. Nas amostras de Açailândia, o silte não apresenta teores detectáveis de gibbsita por difração de raios $X$.

Os componentes principais da fração grosseira $(>63 \mu)$ são fragmentos de dois tipos de gibbsita, pequenos seixos ferruginosos e grãos de quartzo (Figs. 4 e 5). Além desses componentes, foram observados, tanto nos afloramentos quanto sob a lupa binocular, fragmentos bem individualizados de argila. Essas partículas encontram-se, como as outras citadas, espalhadas na matriz argilosa da qual se destacam apenas por seu hábito mais maciço e por sua tonalidade um pouco mais escura. Sua composição mine-

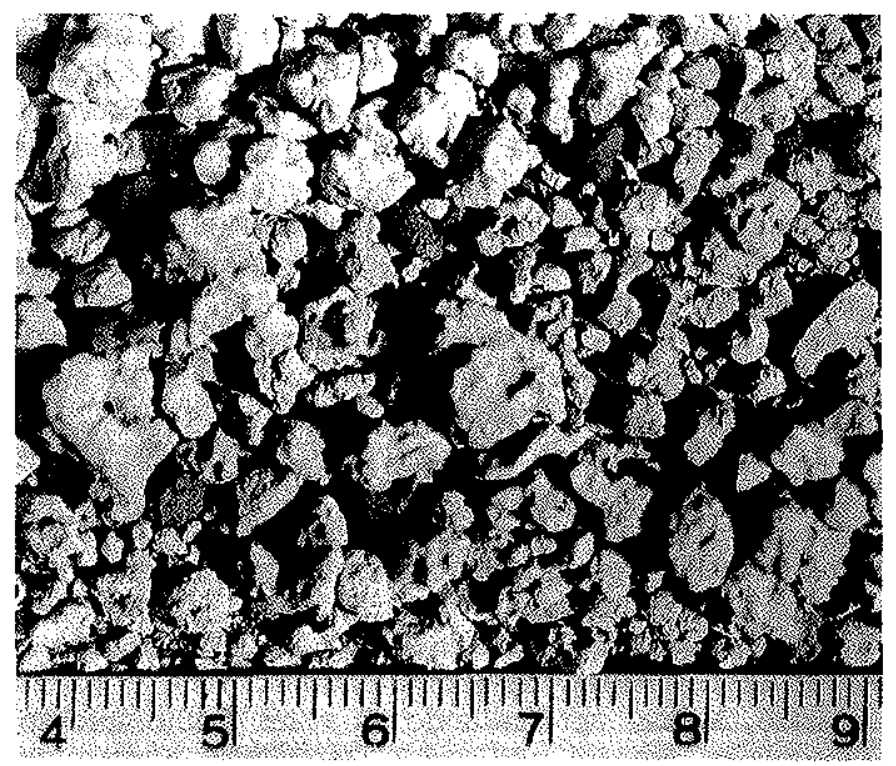

Figura 4 - Fragmentos angulosos de gibbsita porcelanada com poucos grânulos hematíticos (cor escura) da parte inferior da Argila de Belterra (fração $>63 \mu$; perfil de Miltônia). Os frag. mentos gibbsíticos e hematíticos provêm da parte superior da seqüência bauxítica 


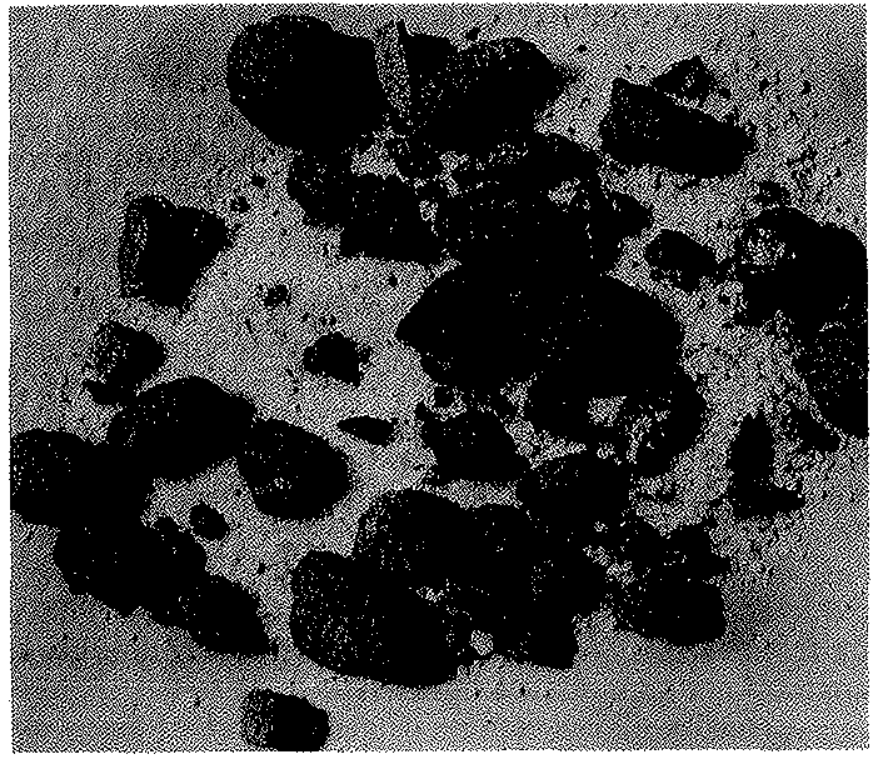

Figura 5 - Grânulos hematíticos e grãos de quartzo da parte inferior da Argila de Belterra (fração $>63 \mu$; perfil de Açailândia). Mesma escala que na Fig. 4

ralógica consiste principalmente em caulinita e subordinadamente em goetita e gibbsita.

A gibbsita da fração grosseira está presente sob forma porcelanada, microcristalina, de cor amarela e esbranquiçada (Fig. 4), e, em quantidade subordinada, sob forma de uma variedade marrom-amarelada, exibindo cristais nitidamente maiores. A gibbsita microcristalina apresenta-se sob forma de indivíduos angulosos e subangulosos até arredondados. A textura interna mostra em geral uma matriz muito fina, cortada, de maneira muito irregular, por microveios de gibbsita de granulação mais grosseira. Certos fragmentos contêm grãos de quartzo que foram parcial ou totalmente substituídos por gibbsita. Pequenas quantidades de caulinita são comuns. A maior quantidade de gibbsita porcelanada encontra-se perto do contato com a bauxita, alcançando em média quase $10 \%$. Nos níveis superiores da Argila de Belterra, a quantidade de gibbsita diminui sem que, todavia, se observe sempre uma variação regular em direção ao topo da sequência. Existe geralmente uma boa correlação entre o tamanho dos fragmentos gibbsíticos e a porcentagem da fração grosseira. Portanto, as partículas maiores ocorrem na parte inferior dos perfis, alcançando até $13 \mathrm{~mm}$ de diâmetro. No topo dos perfis, os grãos maiores raramente ultrapassam $5 \mathrm{~mm}$.

Os fragmentos ferruginosos da fração grosseira são um pouco mais freqüentes nos perfis da região de Paragominas e possuem formas esféricas ou alongadas, bem arredondadas, com diâmetros de até $10 \mathrm{~mm}$ (Fig. 5). O arredondamento é geralmente melhor que o dos fragmentos gibbsíticos. A superfície das partículas ferruginosas varia de cavernosa, devido à dissolução de grãos de quartzo, a lisa, apresentando às vezes brilho intenso. Observa-se também que certos fragmentos apresentam pedaços de gibbsita porcelanada aderida. Os pequenos seixos ferruginosos não mostram textura pisolítica ao microscópio, apenas grãos de quartzo e suas impressões numa massa fina constituída essencialmente de hematita $\mathrm{e}$ goetita. Pela difração de raios $\mathrm{X}$ foram evidenciadas também, em quantidades subordinadas, a caulinita e a gibbsita. Existe a seguinte relação entre as partículas ferruginosas e as de gibbsita: o tipo que prevalece apresenta os grãos maiores.

O quartzo participa em quantidades consideráveis, constituindo às vezes máis de $50 \%$ da fração grosseira (Tab. 2). Os grãos desse mineral são maiores nos sedimentos do Baixo Amazonas que nos da região de Paragominas (Tab. 3). A rocha-fonte das bauxitas mostra também a mesma tendência granulométrica: os sedimentos cretáceos (Formação Itapecuru) da região de Paragominas são mais finos que os do Baixo Amazonas (Formação Alter do Chão).

Tabela 3 - Média dos grãos maiores de quartzo dos perfis da Argila de Belterra

\begin{tabular}{lccc}
\hline Perfil & $\begin{array}{c}\text { No de } \\
\text { amostras }\end{array}$ & $\begin{array}{c}\text { Média } \\
(\mathrm{mm})\end{array}$ & $\begin{array}{c}\text { Desvio- } \\
\text {-Padrão } \\
\text { (mm) }\end{array}$ \\
$\begin{array}{l}\text { A. Baixo } \\
\text { Amazonas }\end{array}$ & & $\cdot$ \\
Nhamundá 1 & 7 & & \\
Nhamundá 2 & 4 & 3,2 & 0,3 \\
Trombetas 1 & 6 & 2,9 & 0,2 \\
B. Região de & & 3,4 & 0,4 \\
Paragominas & & & \\
km 1603 & & & \\
km 1508 & 7 & 2,2 & 0,3 \\
km 1409 & 6 & 1,9 & 0,2 \\
Miltônia & 9 & 2,0 & 0,3 \\
\hline
\end{tabular}

Quanto ao arredondamento dos grãos de quartzo da Argila de Belterra, a maioria é angulosa a subangulosa apresentando fenômenos de corrosão. Entretanto, na seqüência de Açailândia, ocorrem muitos grãos bem arredondados. Além disso, foram observados naquele perfil dois tipos diferentes de quartzo, de cores cinza-clara e amarelada, marcando uma certa "estratificação". É interessante notar que o quartzo dos sedimentos Itapecuru em Açailândia mostra essas mesmas características.

DISCUSSÃO E INTERPRETAÇÃo Proveniência da Argila de Belterra Os dados obtidos mostram que as hipóteses de Sombroek (1966), Klammer (1971) e Wolf e Silva (1973) sobre a origem da Argila de Belterra não podem ser mantidas. Embora Sombroek (1966) tivesse razão de sugerir que esta argila se depositou após a formação da bauxita, a fonte do material na realidade era muito mais próxima que a região andina, como pode ser comprovado pela ligação intima existente entre a sequêencia laterítica e a Argila de Belterra.

Assim, os grãos de quartzo da Argila de Belterra e da litomargem, como também os da rocha-mãe das lateritas de uma mesma região, mostram aspectos granulométri$\cos$ semelhantes, enquanto existem diferenças granulométricas evidentes entre essas mesmas unidades do Baixo Amazonas (quartzo grosseiro) e as da regiåo de Paragominas (quartzo fino e médio). Os grãos arredondados de quartzo e as cores diferentes desse mineral, feições encontradas com freqüência só na Argila de Belterra de Açailândia, na litomargem e na rocha-mãe das lateritas ferruginosas dessa região, sugerem também uma áreafonte próxima para a cobertura argilosa contestando sua origem andina. 
Um outro argumento contra o transporte a partir de áreas distantes do material de Belterra é a grande semelhança quanto ao conteúdo de caulinita e gibbsita fina na Argila de Belterra e na litomargem tanto no Baixo Amazonas como na área de Paragominas e a ausência de gibbsita em cada um desses níveis na região de Açailândia. Os demais constituintes da Argila de Belterra, os pequenos seixos ferruginosos e os dois tipos de fragmentos gibbsíticos provieram de horizontes lateríticos situados acima da litomargem.

Embora haja uma íntima ligação entre a Argila de Belterra e a laterita, essa argila não pode ser interpretada com hase nos modelos de Klammer (1971) e outros autores que a consideram como o horizonte $A$ do perfil laterítico, pois foram observadas partículas quebradas e arredondadas de cimento gibbsítico porcelanado e grânulos ferruginosos com restos aderentes de cimento gibbsítico provenientes da parte superior de perfis bauxíticos (Kotschoubey e Truckenbrodt, 1980), indicando processos de erosão e transporte.

Várias observações opõem-se à hipótese da formação in situ da Argila de Belterra: a presença de diferentes tipos de gibbsita herdados de bauxitas erodidas; a existência de cimento ferruginoso de menisco (Dunham, 1971) ligando os nódulos ferruginosos da parte superior do perfil laterítico de Açailândia; e a presença de superfícies brilhantes (fenômeno semelhante ao verniz do deserto) nos seixos ferruginosos, verificada apenas imediatamente abaixo da Argila de Belterra (Figs. 6 e 7). Os pseudopisolitos e pequenos nódulos situados em posição mais inferior no perfil não apresentam esse brilho. Esse fato leva a admitir uma exposição subaérea da seqüência laterítica, antes da deposição da Argila de Belterra, que é sugerida também pela presença do cimento de menisco. A formação desse cimento sob uma cobertura argilosa é dificilmente aceitável, pois a argila teria penetrado nos interstícios do cascalho ferruginoso impedindo, assim,

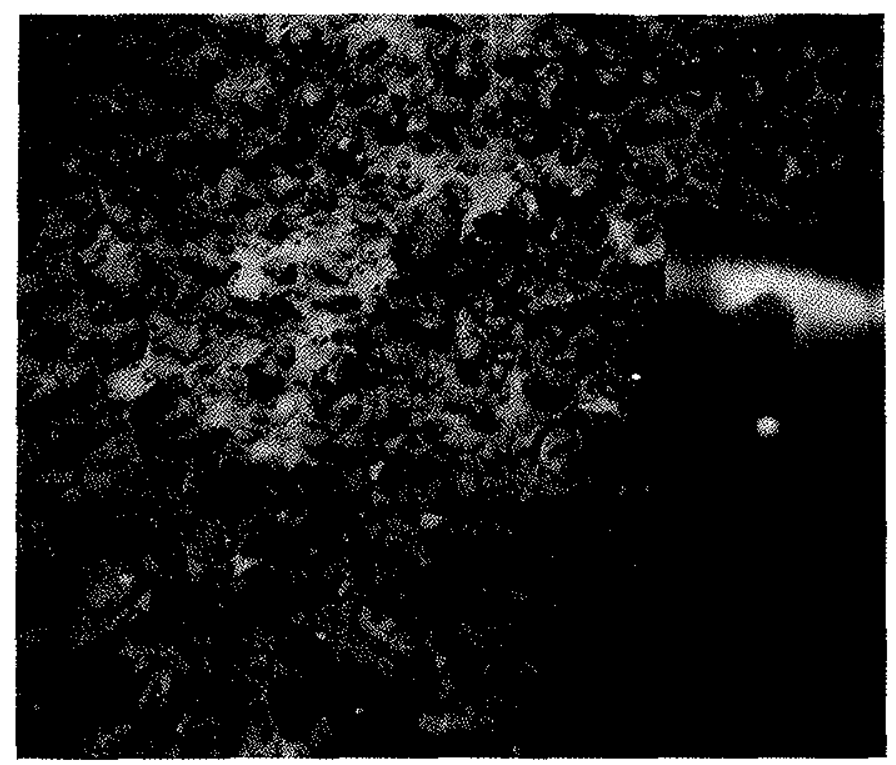

Figura 6 - Detalhe do contato entre a Argila de Belterra e a laterita, próximo a Açailândia (quilômetro 1409). Os pseudopisolitos hematiticos, situados imediatamente abaixo da Argila de Belterra, mostram brilho intenso, semelhante ao verniz do deserto. $O$ objeto escala tem $11 \mathrm{~cm}$ de comprimento

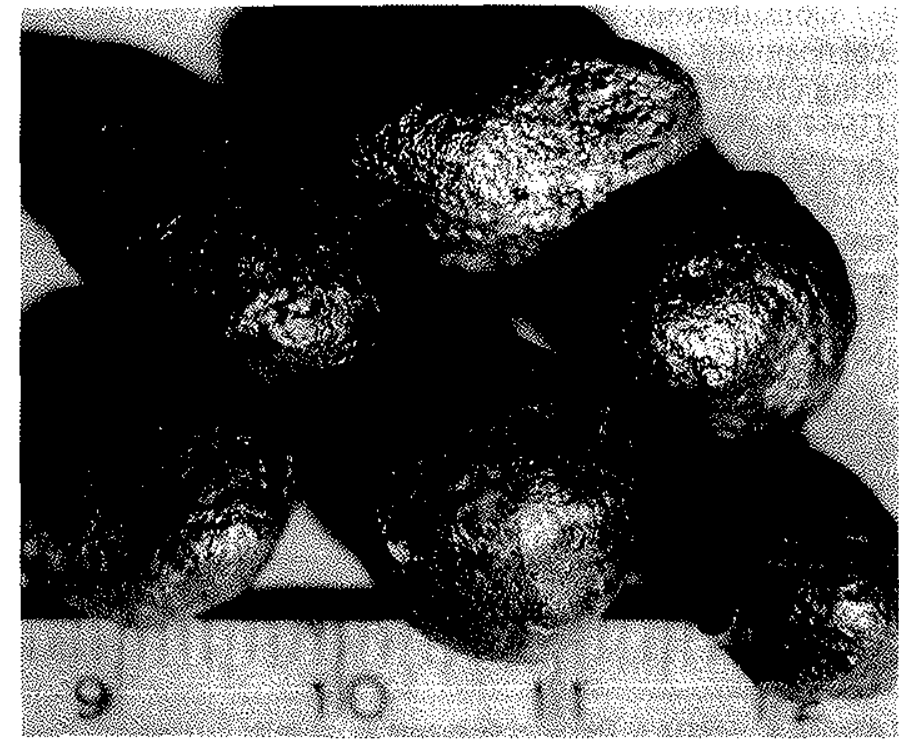

Figura 7 - Detalhe de alguns pseudopisolitos da Fig. 6

esse tipo de cimentação. Os interstícios não ou só parcialmente afetados pela cimentação ferruginosa foram preenchidos mais tarde pela Argila de Belterra.

Considerando todos esses fatos, admite-se que a Argila de Belterra proveio de áreas relativamente próximas de sua zona de deposição e está intimamente ligada à evolução laterítica.

Gênese A laterita é constituída geralmente em sua parte superior por um cascalho ferruginoso, às vezes cimentado e substituido parcialmente por gibbsita. Separada nitidamente da Argila de Belterra, essa laterita representa uma superfície terrestre antiga (Putzer, 1976), que é o resultado final de uma evolução iniciada no Terciário Inferior (Beurlen, 1970; e Krook, 1979).

A textura do cascalho mostra sua origem clástica, atribuída ao desmantelamento de uma crosta ferruginosa durante uma fase de soerguimento e em presença de um clima relativamente árido. Presume-se que o movimento epirogenético continuou desenvolvendo-se principalmente nas zonas mais próximas do Escudo das Guianas e do Craton Amazônico. Em conseqüência desse soerguimento, áreas lateríticas situadas fora e dentro da atual faixa laterito-bauxítica da Amazônia foram erodidas. Assim, o material do horizonte caulínitico e provavelmente da rocha-mãe alterada pode ser transportado segundo o declive natural para zonas mais centrais e depositado em regiões mais baixas, cobrindo áreas lateríticas não erodidas e formando a Argila de Belterra.

A textura da Argila de Belterra, sobretudo os fragmentos gibbsíticos, ferruginosos e argilosos disseminados, sugere uma redistribuição do material argilo-laterítico sob forma de mud flow ou sheet flood. Isso significa uma deposição a partir de fluxos argilosos mais ou menos viscosos sob clima de tendência árida. De acordo com Wilhelmy (1952), existiam nas regiões consideradas, durante o Terciário Superior, um clima semi-árido e uma vegetação aberta, tendo a hiléia amazônica se desenvolvido apenas no Pleistoceno.

Segundo Sombroek (1966), a Argila de Belterra foi depositada durante o Plioceno ou no início do Pleistoceno. 
Considerando sua superfície plana, muito regular, que corresponde ao aplainamento Velhas (IBGE, 1977) de King (1956) ou ao nível $P d_{1}$ segundo Bigarella e Andrade (1964 e 1965), a idade pliocênica, talvez mio-pliocênica, para a Argila de Belterra é aceitável.

$O$ fato de o pediplano da Argila de Belterra ter sido em parte conservado até hoje é devido principalmente ao estabelecimento de vegetação densa no Quaternário, a qual tem retido a argila impedindo seu escoamento em lencol.

Agradecimentos Agradecemos à Mineração Vera Cruz S.A. e à Companhia de Mineração Santarém, especialmente aos geólogos B. Stilianidi Filho, A.A. Gerrits e
C.A. Sá Pereira, pela hospitalidade e pelo valioso auxílio no campo, que permitiram a elaboração do presente trabalho.

Somos também gratos aos nossos amigos Roberto Dall'Agnol e Raimundo Netuno Nobre Villas pela revisão do texto em português e ao pessoal técnico dos laboratórios de Sedimentologia e de Raios-X do NCGG da UFPa pela ajuda nas análises granulométricas e mineralógicas.

Finalmente, expressamos os nossos agradecimentos à Finep pelo apoio financeiro a este trabalho dentro do Projeto Integrado de Pesquisas Geológicas, Geofísicas e Geoquímicas (Verba Finep/UFPa - CT-443).

\section{BIBLIOGRAFIA}

ASSAD, R. - 1973 - Depósitos de bauxita da região de Paragominas, Pará. XXVII Cong. Bras. Geol. Resumos, Bol. 1: 24-25.

BEURLEN, K. - 1970 - Geologie von Brazilian. Berlin, Gebr. Bornträger, 44 pp.

BIGARELLA, J.J. e ANDRADE, G.O. - 1964 - Consideraçð̌es sobre a estratigrafia dos sedimentos cenozócos em Pernambuco (Grupo Barreiras). Univ. Recife, Arq. Inst. Ciên. Terra 2: 2-14.

BIGARELLA, J.J. e ANDRADE, G.O. - 1965 - Contribution to the study of the Brazilian Quaternary. Geol. Soc. Am., Sp. Paper 84: 433-451.

CAROZZI, A. V. - 1958 - Micro-mecanisms of sedimentation in the epicontinental environment. J. Sed. Pet. 38: 133-150.

DAEMON, R.F. - 1975 - Contribuição à dataçâo da Formação Alter do Chão Bacia do Amazonas. Rev. Bras. Geoc. 5: 78-84.

DUNHAM, R.J. - 1971 - Menisciss cement. In: O. P. BRICKER (ed.) "Carbonate Cements", Jobns Hopkins Stud. in Geol. 19: 297-300, Baltimore, Johns Hopkins Press.

DENNEN, W.H. e NORTON, H.A. - 1977 - Geology and geochemistry of bauxite deposits in the lower Amazon Basin. Econ. Geol.72: 82-89.

GRUBB, P.L.C. - 1979 - Genesis of bauxite deposits in the Amazon basin and Guianas coastal plain. Econ. Geol. 74: 735-750.

INSTITUTO BRASILEIRO DE GEOGRAFIA E ESTATISTICA - 1977 Geografia do Brasil, V. 1: Região Norte. Rio de Janeiro, 466 pp.

KING, L.C. - 1956 - A geomorfologia do Brasil Oriental. Rev. Bras. Geogr 18: $147-265$.
KLAMMER, G. - 1971 - Uber plio-pleistozäne Terrassen und ihre Sedimente im unteren Amazonasgebiet. Z. Geomorph. 15: 62-106.

KOTSCHOUBEY, B. e TRUCKENBRODT, W. - 1980 - Gênese das bauxitas do distrito de Paragominas, Pará - Proposta de um modelo evolutivo, XXXI Cong. Bras. Geol., Resumos, Bol. 2: 370

KROOK, K. - 1979 - Sedimentpetrographical studies in Northern Suriname. Amsterdam, Academisch Proefschrift, $154 \mathrm{pp}$.

PUTZER, H. - 1976 - Metallogenetische Provinzen in Südamerika. Stuttgart, Schwejzerbart'sche Verlagsbuchhandlung, $316 \mathrm{pp}$.

SIOLl, H. - 1956 - Sedimentation im Amazonasgebiet. Geol. Rundschau. 45: 608-633.

SOMBROEK, W.G. -1966 - Amazon soils. A reconnaissance of the soils of the Brazilian Amazon region. Wageningen, Centre for Agri, Publ. Document. $292 \mathrm{pp}$.

TRUCKENBRODT, W. e KOTSCHOUBEY, B. - 1980 - Gênese da Argila de Belterra, Terciário Superior, Região Amazônica. XXXI Cong. Bras. Geol. Resumos, Bol, 2: 418 .

WILHELMY, H. - 1952 - Die eiszeitliche und nacheiszeitliche Verschiebung der Klima-und Vegetationszone in Sudanerika. Tag. Ber, u. wiss. Abh. Dt.Geogr. Tage, Frankfurt, 121*128.

WOLF, F.A.M. e SILVA, J.M.R. - 1973 - Província bauxitífera da Amazônia DNPM, S: Distrito, Belém, relat. inédito, $35 \mathrm{pp}$.

Recebido em 23 de abril de 1981

\section{NOTICIÁRIO}

\section{PREPARAC̣ÃO DE MANUSCRITOS PARA A REVISTA - MODIFICAC̣ÕES NAS INSTRUÇÕES AOS AUTORES}

As instruções aos autores para a preparação de manuscritos para a Revista Brasileira de Geociências foram modificadas, a partir deste número, conforme pode ser visto na contra-capa deste exemplar. As mudanças são principalmente as seguintes:

- inclusão de um índice do artigo, logo após o abstract, para permitir à Editora a normalização e seqüenciação dos itens e sub-itens.

- limitação em 70 toques por linha, para o texto.

-... recomendação expressa aos autores para compatibilizar o tamanho das ilustrações com a densidade de informações nelas contidas, prevendo inclusive as reduções que normalmente são feitas. Assim, traços muito finos ou letras de tamanho muito pequeno são restritivos para a redução, pois podem desaparecer ou ficarem ilegiveis no texto impresso.

Estas modificaçôes decorrem da preocupação de se aperfeiçoar cada vez mais o padrão gráfico da Revista. 